\title{
Preparing for pandemic (H1N1) 2009
}

$\mathrm{W}$

e must not underestimate an enemy like pandemic (H1N1) 2009, especially now. This influenza pandemic has already created havoc in communities worldwide, including some in Canada. The virus's place of origin, the speed of its spread and the severity of the illness in otherwise healthy people could not be foreseen before the initial outbreaks, even by experts. In addition, containment, a first step in the control of an outbreak, has failed.

The pandemic (H1N1) 2009 virus is life-threatening for some patients and mild for most who are infected. If the disease continues to evolve in the northern hemisphere as it is has in the southern hemisphere, especially in Chile and Australia, we will probably experience a more severe resurgence this coming influenza season. Most industrialized countries have already put their pandemic plans into action, to good effect. However, based on round one, we should plan for important increases in pandemic (H1N1) 2009 cases that manifest at the two ends of the spectrum of disease severity.

Obviously, prevention through immunization should remain our top priority. However, we must identify vulnerable or at-risk groups as a first step. Then, we must decide how best to vaccinate these groups.

Canada and much of the Western world have limited experience in conducting time-sensitive mass vaccination campaigns. We already have problems delivering routine influenza vaccination to vulnerable groups. For instance, in some years only $15 \%$ of individuals in Nunavut communities received the vaccine. ${ }^{1}$ During the most recent outbreak of mumps among young adults in Nova Scotia, only $15 \%$ of targeted individuals were vaccinated. ${ }^{2}$ This is the same age group likely to be severely affected in the upcoming second wave of pandemic (H1N1) 2009. We need to act now to overcome these access and delivery problems.

No immunization program is $100 \%$ effective. If a sufficient number of cases are not prevented, we can expect a large number of young critically ill patients filling all tertiarylevel intensive care beds. Unlike most seasonal influenza strains, this pandemic (H1N1) 2009 strain seems to invade the lower airway and alveoli, not just the upper airways, resulting in more severe illness. ${ }^{3,4}$ The world's experience so far tells us that serious illness associated with this virus often manifests as acute lung injury resulting in overwhelming hypoxemia. Advanced life-support technologies, including highfrequency oscillation, extracorporeal membrane oxygenation and nitric oxide for prolonged periods are often required to save these young lives.

All of these technologies require highly specialized care in

\section{National action plan}

- Ensure that all stakeholders are engaged and collaborate with modified action plans as a first line of defence.

- Identify a health care czar with power and legal authority to address national emergencies and act at all levels of government as a second line of defence.

- The health czar must be trusted by the highest office in the land, have direct access to power and be sufficiently independent to make unpopular but necessary decisions.

- Prioritize groups to receive vaccination and roll out mass vaccination plans.

- Develop clear surge plans to ensure mobility of health professionals and specialized equipment.

- Direct all sectors of society to create personal pandemic action plans.

- Ensure rapid review and allocation of new research funds to answer critical questions about pandemic (H1N1) 2009.

tertiary centres. These resources are limited and can easily be overwhelmed. If they are, major health care institutions could grind to a halt.

In most jurisdictions, surge planning has not yet included how to secure experienced health care personnel and triage specialized equipment. We will also need to make hard decisions about who gets access to these limited resources. Now is the time for leaders to communicate a sense of urgency in getting modified plans finalized based on recent experiences and rapid feedback from stakeholders.

To start, national leadership is needed in all countries. A visible independent health care czar, with executive powers across all jurisdictions and who is ultimately accountable to the highest office in the country, must be in place. Then, local leaders must be identified. All stakeholders should have clear communication with and rapid access to experts. We need leaders at all levels who will work together quickly and collaboratively to solve problems such as moving equipment and personnel from one area of a country to another as required without barriers imposed by licensing, hospital privileges and malpractice insurances concerns.

In countries such as Canada that have shared responsibilities between many levels of government, collaboration and clear communication are essential as a first line of defence. To see that this happens, governments need to have or enact laws to provide the necessary power to ensure rapid action on complex issues.

A health czar should also make sure that researchers have 
the money needed now to answer the urgent outstanding questions about this emerging health threat, such as why specific groups are more susceptible, and to identify treatments that work best.

The health czar needs to communicate to all sectors of society that everyone has the responsibility to make an individual pandemic action plan: governments at all levels (including the municipal level), schools, daycares, businesses, families and individuals. For example, we should adopt the United Kingdom's approach of creating a "flu buddy" system, where individuals partner with one another to take responsibility for checking on each other's health status.

This is not a time for complacency. The health czar and other national leaders should immediately convene a summit to link public health officials, the critical care community, first responders, other health care providers, decision-makers, community planners and the public, to communicate next steps and to ensure that actions taken by leaders will work at the ground level. While we still hope for the best, we need to act now to deal with the worst that pandemic (H1N1) 2009 may deliver. Doing so will save lives.
Paul C. Hébert MD MHSc

Editor-in-Chief

Noni MacDonald MD MSc

Section Editor, Public Health

CMAJ

With the Editorial-Writing Team (Matthew B.

Stanbrook MD PhD, Ken Flegel MDCM MSc, Amir Attaran LLB DPhil, Laura Eggertson BA)

Competing interests: See www.cmaj.ca/misc/edboard.shtml

Cite as CMAJ 2009. DOI:10.1503/cmaj.091545

\section{REFERENCES}

1. Steenbeek A, MacDonald NE, Sobel I. Influenza vaccine use in Nunavut: A brief overview of the uptake rates across the regions [letter]. Can J Public Health. In press.

2. Hatchette TF. Students, saliva and swelling: a perfect storm for the sharing of mumps. Presented at the annual conference of the Association of Medical Microbiology and Infectious Disease Canada, Vancouver, Canada; 2008 Mar. 1. Available: www.ammi.ca/pdf/2008_ToddHatchette.pdf (accessed 2009 Aug. 5)

3. Munster VJ, de Wit E, van den Brand JM, et al. Pathogenesis and transmission of swine-origin 2009 A(H1N1) influenza virus in ferrets. Science 2009;325:481-3.

4. Maines TR, Jayaraman A, Belser JA, et al. Transmission and pathogenesis of swineorigin 2009 A(H1N1) influenza viruses in ferrets and mice. Science 2009;325:484-7. 